\title{
CONCEITUANDO A EDUCAÇÃO A DISTÂNCIA ${ }^{\mathrm{I}}$
}

\begin{abstract}
Antonia Izabel da Silva Meyer ${ }^{2}$
RESUMO: Na atualidade a educação a distância é vista como um processo de ensino aprendizagem, mediada pelo uso das novas tecnologias de informação e comunicação, onde alunos e professores encontram-se separados pela distância espaço-temporal. Na literatura acadêmica muitos autores fizeram tentativas de conceituar nesta modalidade de ensino, apresentando pontos em comum enfatizando algumas características. Essa pesquisa tem como objetivo analisar na literatura acadêmica os conceitos de Educação a distância conforme alguns autores descrevem, assim suas características e os modelos predominantes na literatura. Utilizou-se como metodologia uma pesquisa bibliográfica em livros e artigos científicos com autores relacionados com esta temática. Resultando que os conceitos $e$ as característica da $\mathrm{EaD}$ enfatizam o espaço-tempo, uso das tecnologias para comunicação e interação, uma maior autonomia por parte do aluno em administrar sua aprendizagem e a importância dos processos de ensino-aprendizagem e sua adequação aos modelos pedagógicos.
\end{abstract}

Palavras-chave: Educação. Educação a Distância. Características da EaD.

ABSTRACT: Currently, distance education is seen as a teaching-learning process, mediated using new information and communication technologies, where students and teachers are separated by the spatiotemporal distance. In academic literature, many authors have attempted to conceptualize this type of teaching, presenting common points, and emphasizing some characteristics. This research aims to analyze in the academic literature the concepts of Distance Education as some authors describe, thus its characteristics and the predominant models in the literature. Bibliographical research in books and scientific articles with authors related to this theme was used as a methodology. Resulting that the concepts and characteristics of distance education emphasize space-time, use of technologies for communication and interaction, greater autonomy on the part of the student to manage their learning and the importance of teaching-learning processes and their adequacy to pedagogical models.

Keywords: Education. Distance Education. Characteristics of Distance Education.

${ }^{\mathrm{I}}$ Este artigo foi construído a partir da fundamentação teórica e reflete dados bibliográficos parciais da Tese em construção em Ciências da Educação pela Universidad Autónoma de Asunción - UAA (2022) Paraguai - (PY).

${ }^{2}$ Doutoranda em Ciências da Educação pela Universidad Autonóma de Asunción - UAA (2018). Mestre em Educação pela Universidad del Desarrollo Sustentable (2017). MBA em Gestão de Pessoas pela Faculdade Joaquim Nabuco. Possui graduação em Ciências da Informação com Habilitação em Biblioteconomia pela Universidade Federal de Alagoas - UFAL. 


\section{INTRODUÇÃO}

A Educação a Distância é caraterizada como uma modalidade de ensino onde os professores e os alunos, encontram-se separados pelo espaço e tempo, tendo evoluído com o tempo e de acordo com os avanços científicos e tecnológicos disponíveis. Com o advento das novas Tecnologias da Informação e Comunicação TICs, vem diversos ambientes digitais que permitem a aprendizagem dos alunos de forma on-line.

$\mathrm{Na}$ atualidade a educação a distância é vista como um processo de ensino aprendizagem, mediada pelo uso das novas tecnologias de informação e comunicação, onde alunos e professores encontram-se separados pela distância espaço-temporal. Assim, educação à distância é uma modalidade de educação muito utilizada na educação básica, em cursos de capacitação, na educação superior, em cursos abertos, cursos de pós-graduação, entre outros.

Tendo como caraterística o espaço-temporal, a flexibilização do tempo a utilização da Internet através de plataformas virtuais, que permitem uma proposta pedagógica desenvolvida de acordo com o curso ou disciplina.

Essa pesquisa tem como objetivo analisar na literatura acadêmica os conceitos de Educação a distância conforme alguns autores descrevem, assim suas características e os modelos predominantes na literatura. Mostraremos os conceitos de $\mathrm{EaD}$ seguindo uma ordem cronológica através de vários autores enfatizando alguns pontos comuns e suas características.

$\mathrm{O}$ artigo trata-se de uma pesquisa bibliográfica, a qual foi realizada através de revisão de literatura de artigos científicos e livros já publicados, que discutem sobre a temática, os quais contribuíram para uma maior fundamentação do tema. Gil (2018) destaca que a principal vantagem da pesquisa bibliográfica reside no fato de permitir ao investigador a cobertura de uma gama de fenômenos muito mais ampla do que aquela que poderia pesquisar diretamente. Assim, alguns teóricos são abordados na fundamentação da pesquisa.

I Conceitos da Educação à Distância

A educação a distância (EAD) é uma realidade e já vem sendo realizada desde o século XVIII, através dos cursos por correspondência. Entretanto, as primeiras 
experiências com a educação a distância institucionalizada, surgiram no início do século XIX, em vários países, assim, a EAD torna-se importante em oferecer educação a lugares distantes e, também atender a uma demanda da população que não podem conciliar sua rotina ao modelo presencial de estudo.

$\mathrm{Na}$ literatura acadêmica muitos autores fizeram tentativas de conceituar nesta modalidade de ensino, apresentando pontos em comum enfatizando algumas características. Fundamentado na cronologia de conceitos traçado por Bernardo (2009 apud ALVES, 20II; OLIVEIRA, 2014) para apresentar a evolução dos conceitos da EaD, destacando:

O conceito de Dohmem em 1967, que enfatiza a forma de estudo na Educação a Distância:

Educação a Distância é uma forma sistematicamente organizado de autoestudo onde o aluno instrui-se a partir do material de estudo que lhe é apresentado, o acompanhamento e a supervisão do sucesso do estudante são levados a cabo por um grupo de professores. Isto é possível através da aplicação e meios de comunicação, capazes de vencer longas distâncias.

O Conceito de Peters em 1973 ressalta a metodologia da Educação e a industrialização do processo de ensino-aprendizagem:

Educação/ensino a distância é um método racional de partilhar conhecimento, habilidades e atitudes, através da aplicação da divisão do trabalho e princípios organizacionais, tanto quanto pelo uso extensivo e meios de comunicação, especialmente para reproduzir materiais técnicos de alta qualidade, os quais tornam possível instruir um grande número de estudantes ao mesmo tempo, enquanto esses materiais durarem. É uma forma industrializada de ensinar e aprender.

O conceito de Moore em 1973, destaca que as ações do professor e a comunicação destes com os alunos devem ser facilitadas:

Ensino a distância pode ser definido como a família de métodos instrucionais onde as ações dos professores são executadas à parte das ações dos alunos, incluindo aquelas situações continuadas que podem ser feitas na presença dos estudantes. Porém, a comunicação entre professor e os alunos deve ser facilitada por meios impressos, eletrônicos, mecânicos ou outro.

O conceito de Holmberg em 1977, enfatiza a diversidade das formas de estudo:

O termo Educação a Distância esconde-se sob várias formas de estudo, nos vários níveis que não estão sob a contínua e imediata supervisão de tutores presentes com seus alunos nas salas de leitura ou no mesmo local. A educação a Distância beneficiase do planejamento, direção e instrução da organização do ensino. 
O conceito de Keegan em 1991, destaca-se pela separação física entre professor

e aluno e a possibilidade de encontros ocasionais:

O autor define a Educação a Distância como a separação física entre professor e alunos, que a distingue do ensino presencial; influência da organização educacional (planejamento, sistematização, plano, organização dirigida, etc.), que diferencia da educação individual; utilização de meios técnicos de comunicação para unir professor ao aluno e transmitir conteúdos educativos; previsão de uma comunicação de mão dupla, onde o estudante beneficia-se de um diálogo e da possibilidade de iniciativas de dupla via com possibilidade de encontros ocasionais com propósitos didáticos e de socialização.

Conceito de Chaves em 1999, é caracterizado por ressaltar a separação física e o uso de tecnologias de telecomunicação:

A Educação a Distância, no sentido fundamental da expressão, é o ensino que ocorre quando o ensinante e o aprendente estão separados (no tempo e no espaço). No sentido que a expressão assume hoje, enfatiza-se mais a distância do espaço e propõe que ela seja contornada através do uso das tecnologias de telecomunicação e de transmissão de dados, voz e imagens (incluindo dinâmicas, isto é, televisão ou vídeo). Não é preciso ressaltar que todas essas tecnologias, hoje, convergem para o computador (BERNARDO, 2009 apud OLIVEIRA, 2014, p. 17-18, ALVES, 2011, p. $85)$.

No Brasil o conceito de Educação a Distância é caracterizado pelo Decreto $\mathrm{n}^{\mathrm{0}} 5.622$ de 19 de dezembro de 2005 , descreve no primeiro Artigo:

A educação a distância como modalidade educacional na qual a mediação didático-pedagógica nos processos de ensino e aprendizagem ocorre com a utilização de meios e tecnologias de informação e comunicação, com estudantes e professores desenvolvendo atividades educativas em lugares ou tempos diversos (BRASIL, 2005).

Essa descrição oficial retrata as discussões de diferentes autores sob as mudanças de paradigma da educação presencial, mostrando os meios e estratégias utilizados na $\mathrm{EaD}$, onde o ensino e a aprendizagem não estão mais restritos ao momento presencial entre professor e aluno.

Surgiram outros conceitos dessa modalidade de ensino, enfatizando as tecnologias e a separação espaço/tempo, entre elas, podemos ressaltar, que a educação a distância

É ensino/aprendizagem onde professores e alunos não estão normalmente juntos, fisicamente, mas podem estar conectados, interligados por tecnologias, principalmente as telemáticas, como a Internet. Mas também podem ser utilizados o correio, o rádio, a televisão, o vídeo, o CD-ROM, o telefone, o fax e tecnologias semelhantes (MORAN, 2002, p. I).

De acordo com ao autor "a educação a distância pode ter ou não momentos presenciais, mas acontece fundamentalmente com professores e alunos separados 
fisicamente no espaço e ou no tempo, mas podendo estar juntos através de tecnologias de comunicação" (MORAN, 2002, p. I).

De acordo com Maia e Mattar (2012, p. 5) "a EAD é uma modalidade de educação em que professores e alunos estão separados, planejado por instituições e que utiliza diversas tecnologias de comunicação". Os autores conceituam a educação a distância como a educação que:

Possibilita manipulação do espaço e do tempo em favor da educação. $O$ aluno estuda onde e quando quiser e puder. Pode, por exemplo, passar algumas sem se dedicar muitos aos estudos, por diversos motivos, e durante uma ou duas semanas, então, dedica-se com mais energia. Ou seja, o aluno se auto programa para estudar, de acordo com seu tempo e disponibilidade (MAIA e MATTAR, 2012, p. 7).

Percebe-se que as definições referenciadas sob EAD estão voltadas na sua maioria ao uso das tecnologias para comunicação e interação e para a separação espaço/tempo entre professores e alunos. Não evidenciando a importância dos processos de ensino-aprendizagem e sua adequação aos modelos pedagógicos, recursos e metodologia de ensino.

$\mathrm{Na}$ Educação a Distância (EAD)

O processo de desenvolvimento pessoal e profissional no qual os professores e os estudantes interagem virtual ou presencialmente, por meio da utilização didática das tecnologias de informação e comunicação, bem como de sistemas apropriados de gestão e avaliação, mantendo a eficácia do ensino e da aprendizagem (MAIA e MATTAR, 2012, p. 29).

Os autores salientam para a interação e a utilização de didáticas no processo de ensino e aprendizagem mediados pelo uso das tecnologias.

Sem dúvida, a educação a distância, por sua experiência no ensino com metodologias não presenciais, pode vir a contribuir inestimavelmente para a transformação dos métodos de ensino e da organização do trabalho nos sistemas convencionais, bem como para a utilização adequada das tecnologias de midiatização da educação. [...] A experiência e o saber desenvolvidos no campo da educação a distância podem trazer contribuições significativas para a expansão e melhoria dos sistemas de ensino superior no sentido da convergência, defendida pela maioria dos especialistas, entre as diferentes modalidades da educação: o cenário mais provável no século XXI será o sistema de ensino superior "misto" ou integrados", que oferecem oportunidades diversificadas de formação, organizáveis de modo flexível, de acordo com as possibilidades do aluno, com atividades presenciais e a distância, com uso intensivo de tecnologias e com atividades presenciais, [...] que trabalharão de modo cooperativo (BELLONI, 2016, p. 6-7). 
Neste contexto, a educação a distância, vem a contribuir nas mudanças dos métodos de ensino, na aprendizagem significativa e colaborativa, tanto na modalidade presencial quanto à distância.

\section{Características da EAD}

A Educação a Distância é caracterizada principalmente pela separação entre professor e aluno no tempo e espaço, sendo outra característica importante uma maior autonomia por parte do aluno em administrar sua aprendizagem (autoaprendizagem). As interações mediadas por tecnologias é outra característica da EAD, apresenta a flexibilidade de horário; ensino personalizado; Ambientes Virtuais de Aprendizagem, tendo também como características as comunicações assíncronas e síncronas.

De acordo com Sartori (2002), os pontos fundamentais que caracterizam a Educação a Distância são:

a) Simultaneidade entre estudo e trabalho - o aluno consegue estabelecer horários de estudo que não impliquem em seu trabalho, criando autonomia em seus estudos, uma vez que não precisa estar presencialmente na instituição para estudar.

b) Desenvolvimento da autonomia nos estudos - o aluno pode estabelecer horários e locais que lhes são convenientes e oportunos, respeitando o seu ritmo de aprendizagem.

c) Desenvolvimento da capacidade auto organizativa - o aluno tem autonomia para organizar e autogerenciar seus estudos.

d) Interatividade e trabalho colaborativo - a interatividade acontece entre professores e alunos por meio da tecnologia e essa mesma interatividade proporciona o surgimento do trabalho colaborativo entre os alunos (SARTORI, 2002).

Preti (1996) apresenta a definição de Garcia Aretio (1994), destacando os seguintes elementos:

Distância física professor-aluno: a presença física do professor ou do tutor, isto é, do interlocutor, da pessoa com quem o estudante vai dialogar, não é necessária e indispensável para que se dê a aprendizagem. Ela se dá de outra maneira, mediada por tecnologia de comunicação, "virtualmente" (ARETIO, 1994 apud PRETI, 1996).

Estudo individualizado e independente: reconhece-se a capacidade do estudante de construir seu caminho, seu conhecimento por ele mesmo, de se tornar 
autodidata, ator e autor de suas práticas e reflexões (ARETIO, I994 apud PRETI, 1996).

Processo de ensino-aprendizagem mediatizado: a EAD deve oferecer suporte e estruturar um sistema que viabilize e incentive a autonomia dos estudantes nos processos de aprendizagem (ARETIO, 1994 apud PRETI, 1996).

Uso de novas tecnologias: os recursos técnicos de comunicação, que hoje têm alcançado um avanço espetacular - correio, rádio, TV, audiocassete, hipermídia interativa, internet -, permitem romper as barreiras das distâncias, das dificuldades de acesso à educação e dos problemas de aprendizagem por parte dos alunos que estudam individualmente, muito embora não isolados e sozinhos. São essas tecnologias que oferecem possibilidades de estímulo e motivação ao estudante, de armazenamento e divulgação de dados, de acesso às informações mais distantes e com uma rapidez incrível (ARETIO, 1994 apud PRETI, 1996).

Comunicação bidirecional: o estudante não é mero receptor de informações, de mensagens. Apesar da distância, busca-se estabelecer relações dialógicas, criativas, críticas e participativas (ARETIO, I994 apud PRETI, 1996).

Para que ocorra o processo de ensino e aprendizagem professor e aluno não precisam estar fisicamente no mesmo local e tempo, com a separação temporal as atividades podem ser realizadas de forma assíncrona. $\mathrm{O}$ uso das novas tecnologias elimina o caráter temporal e geográfico no processo desse processo podemos entender que na atualidade existem três formas de Educação (MORAN, 2002):

A presencial - dos cursos regulares, em que professores e alunos se encontram sempre num local físico chamado sala de aula. É o ensino convencional; A semipresencial - acontece em parte na sala de aula e outra parte a distância, por meio de tecnologias; A Educação a Distância - pode ter momentos presenciais (ou não); acontece fundamentalmente com professores e alunos separados fisicamente no espaço e/ou no tempo, mas que podem estar juntos por meio de tecnologias de comunicação (MORAN, 2002).

A Educação a Distância, como observamos é modelo de educação fundamentalmente não presencial que se distingue, sob vários aspectos, da educação presencial. Várias características e propriedades da educação presencial podem não se 
aplicar a EAD. Contudo, algumas características desse modelo podem atualmente ser aplicadas no ensino presencial, pois ele pode ou não ter uma parte da sua carga horária em momentos não presenciais, conforme a portaria do MEC n⿳0 1.428 de 28 de dezembro de 2018 (BRASIL, 2018). Especialmente, pelas mudanças nas práticas pedagógicas evidenciadas pelas experiências com as TICs na EAD.

3 Modelos predominantes de EAD

A Educação a Distância transpôs por diversas tentativas de estabelecer-se, sem conseguir alcançar uma grande repercussão no decorrer do tempo, porém, na atualidade com a inserção das novas tecnologias de informação e comunicação a qual vêm modificando as formas de aprender e ensinar, proporcionando a produção do conhecimento de modo mais abrangente, tendo um papel essencial nos modelos atuais da EAD.

O Brasil se encontra em uma fase de consolidação da Educação a Distância no ensino superior, assim, um curso em EAD apresenta uma organização, dinâmica e estrutura um pouco singular do ensino presencial. Entre elas, estão a distância física entre professores e alunos, a comunicação mediada por recursos tecnológicos de forma assíncrona e síncrona, a flexibilização do tempo.

Segundo Moran (2009), essencialmente temos três modelos principais de EAD no ensino superior brasileiro com algumas variáveis e combinações: o modelo teleaula, o modelo videoaula e o modelo web. Assim segundo o autor:

Modelo Tele aula - Esse modelo é caracterizado pela transmissão de aulas via satélite, cujas interações ocorrem via internet. Os alunos se reúnem em salas e um professor transmite uma ou duas aulas por semana, ao vivo. Os alunos enviam perguntas e o professor responde aquela que considera mais importantes. Em geral, depois das aulas os alunos se reúnem em pequenos grupos, para realizar algumas atividades de discussão e aprofundamento de questões relacionadas com a aula dada sob a supervisão de um mediador, chamado professor-tutor-local. Além das aulas, os alunos costumam receber material impresso e orientação das atividades durante a semana, individualmente, com o acompanhamento de um professor-tutor on-line ou eletrônico (MORAN, 2009). 
Esse modelo começou focando mais a transmissão, a tecnologia de satélite, a multiplicação dos polos onde eram instaladas as teles salas. As aulas são variações de professores falando - com ilustrações de Power Point, trechos de vídeo e alguma interação em lousa digital. Os textos das aulas estão e livros impressos ou digital (CD, DVD ou Internet). além das tele aulas e das atividades locais os alunos acessam (quando podem) o portal do curso na Internet, onde encontram alguns materiais complementares, realizam alguma interação - em geral por fórum - e enviam sua atividade para o tutor on-line (MORAN, 2009).

Esse é o modelo que os tutores têm um papel importante, visto que, eles são os que acompanham os alunos nas suas atividades individuais e em grupo, assistem as aulas, tiram dúvidas e fazem comentários sobre a realização desses alunos em um portfólio eletrônico. E durante toda a semana acompanham os alunos que vão aos polos para pesquisar no laboratório. Existe a figura do coordenador pedagógico do polo para todos os cursos, ele é o responsável institucional pelo andamento dos cursos no local, coordena as atividades dos tutores e supervisiona a infraestrutura e o desenvolvimento acadêmico (MORAN, 2009).

Modelo videoaula - Há dois modelos predominantes na videoaula o semipresencial e outro on-line. O modelo mais utilizado é o de teles sala, em que o aluno vai presencialmente uma ou várias vezes por semana e um tutor supervisiona a exibição do vídeo e as atividades relacionadas ao conteúdo das disciplinas. Este também é o responsável por tirar as dúvidas dos alunos, sob a coordenação do professor responsável pela disciplina. Esse modelo é muito útil, principalmente para cidades pequenas, sem condições para instalação de uma instituição de ensino superior local (MORAN, 2009).

Outro modelo é com videoaulas, em que os alunos acessam via web ou recebem um CD ou DVD. Os alunos assistem as aulas às videoaulas em casa ou no trabalho, leem o material impresso e fazem as atividades que serão entregues a um tutor - on-line, num ambiente de aprendizagem digital, em geral o Moodle. Os alunos só vãos aos polos para as avaliações on-line (MORAN, 2009).

O modelo semipresencial é muito utilizado nos cursos de pedagogia licenciatura, porém, com as novas regras do MEC relacionadas à infraestrutura, as 
instituições precisam adaptar-se às normas vigentes. A infraestrutura de apoio administrativa, tecnológica e acadêmica, costuma ser precária, com poucos computadores, biblioteca diminuta, tutor sozinho com os alunos (MORAN, 2009).

Modelo via WEB - Atualmente quase todos os cursos superiores a distância, utilizam em algum momento a Internet, só que existem instituições que têm nela seu principal suporte (MORAN, 2009).

O modelo web foca o conteúdo disponibilizado pela Internet e por CD ou DVD. Além do material na web, os alunos costumam ter material impresso por disciplina ou módulo. Os ambientes principais de aprendizagem são o Moodle, o BlackBoard e o Teleduc. Algumas instituições têm seu próprio ambiente digital de aprendizagem. Começa-se a utilizar a web conferência para alguns momentos de interação presencial com os alunos, para orientações, dúvidas e manutenção de vínculos afetivos (MORAN, 2009).

Moran (2009) identifica duas subdivisões do modelo web no ensino superior à distância: o modelo mais virtual e semipresencial. No modelo virtual, a orientação dos alunos é feita a distância via Internet ou telefone. Os alunos se reportam ao professor ou ao tutor durante o semestre e geralmente se encontram apenas para as avaliações. Nesse modelo tudo acontece pela internet, através dos ambientes virtuais.

No modelo semipresencial, o autor exemplifica como o do Consórcio Centro de Educação Superior à Distância do Estado do Rio de Janeiro-Cederj das Universidades Públicas do Estado do Rio de Janeiro, os alunos têm polos perto de onde moram e, além do tutor on-line, têm o tutor presencial no polo, com quem podem tirar dúvidas, participar de atividades solicitadas e do laboratório de informática e específicos do curso. Esse modelo é replicado pelas universidades públicas, sob a gestão da UAB que fazem parceria com as prefeituras para a instalação de polos de apoio presenciais (MORAN, 2009).

De acordo com Nunes (1994 apud ALVES, 2011, p. 84),

A Educação a Distância constitui um recurso de incalculável importância para atender grandes contingentes de alunos, de forma mais efetiva que outras modalidades e sem riscos de reduzir a qualidade dos serviços oferecidos em decorrência da ampliação da clientela atendida. 
Com a utilização de tecnologias de comunicação, a Educação à Distância atinge a um número maior de alunos, sem perder sua qualidade. Estabelecendo novas possibilidades no processo de ensino e aprendizagem.

\section{CONSIDERAÇÕES FINAIS}

A educação a distância vem sendo praticada de acordo com as tecnologias existentes em cada época. Ela também atender a uma demanda da população que não podem conciliar sua rotina ao modelo presencial de estudo. Através desta pesquisa, podemos os conceitos dos autores ao logo dos nãos que norteia a educação a distância.

Os autores evidenciam nos seus conceitos o estudo da $\mathrm{EaD}$, a metodologia utilizada no processo de ensino-aprendizagem, as práticas dos professores e a comunicação com os alunos, além da separação física e temporal entre professor e aluno.

Os modelos de educação a distância são definidos principalmente pela forma de interação e ferramentas utilizadas para comunicação entre os integrantes do curso, assim com a estrutura pedagógica do curso é totalmente on-line ou semipresencial.

Portanto, percebe-se que os conceitos e as característica da EaD enfatizam o espaço-tempo, uso das tecnologias para comunicação e interação, uma maior autonomia por parte do aluno em administrar sua aprendizagem e a importância dos processos de ensino-aprendizagem e sua adequação aos modelos pedagógicos.

\section{REFERÊNCIAS}

ALVES, L. Educação a distância: conceitos e história no Brasil e no mundo. Associação brasileira de educação a distância. (v.ro.), 2011. Disponível em: http://www.abed.org.br/revistacientifica/Revista_PDF_Doc/20II/Artigo_07.pdf. Acessado em Acessado em ro de novembro de 2019

BELLONI, M. L. Educação a distância. Campinas, SP: Autores Associados, 2016.

BRASIL. Presidência da República. Secretária-Geral. Subchefia para Assuntos Jurídicos. Decreto $n^{\underline{0}}$ 5.622/2005, 2005. Disponível em: http://portal.mec.gov.br /portarias/dec5.622.pdf. Acessado em is de dezembro de 2019.

BRASIL. (2018). Ministério da Educação. Gabinete do Ministro. Portaria $n^{0}$ I. 428/2018,2018. Disponível em: http://www.in.gov.br//content/id/57496468/dor-2018-12- 
31-portaria-n-I-428-de-28-de-dezembro-de-2018-5749625I. Acessado em i5 de dezembro de 2019.

GIL, A.C. Como elaborar projetos de pesquisa. 6⿳亠丷厂 ed. São Paulo: Atlas, 2018.

MAIA, C., MATTAR, J. ABC da EaD: a educação a distância hoje. São Paulo: Pearson, 2012.

MORAN, J. O que é a educação a distância 2002. Disponível em: http://www2.eca.usp.br/moran/wp-content/uploads/2013/12/dist.pdf. Acessado em o8 de janeiro de 2020

MORAN, J. M. O ensino superior à distância no Brasil. Educação dr Linguagem. v. I2. n. 19. p. 17-35. jan.-jun., 2009.

OLIVEIRA, M. S. de. A história da Educação à Distância e contexto atual. In: COElHO, F. J. F.; VElloSO, A; (Org.). Educação à Distância: história, personagens e contextos. Curitiba: CRV, 2014.

PRETI, O. Educação a distância: uma prática educativa mediadora e mediatizada. In: Preti, O. Educação a Distância: inícios e indícios de um percurso. Cuiabá: NEAD/IE-UFNT, 1996.

SARTORI, A. S. Metodologia da educação a distância. Florianópolis: UDES/CEAD, 2002. 